\title{
Heritabilitas, Karakterisasi, dan Analisis Clustergram Galur-galur Padi Dihaploid Hasil Kultur Antera
}

\author{
Heritability, Characterization, and Clustergram Analysis \\ of Doubled Haploid Rice Lines Derived from Anther Culture
}

\section{Muhammad Fuad Anshori ${ }^{1}$, Bambang Sapta Purwoko ${ }^{2 *}$, Iswari Saraswati Dewi ${ }^{3}$, Sintho Wahyuning Ardie ${ }^{2}$, Willy Bayuardi Suwarno², dan Heni Safitri ${ }^{4}$}

\author{
${ }^{1}$ Program Studi Pemuliaan dan Bioteknologi Tanaman, Sekolah Pascasarjana, Institut Pertanian Bogor \\ ${ }^{2}$ Departemen Agronomi dan Hortikultura, Fakultas Pertanian, Institut Pertanian Bogor \\ (Bogor Agricultural University), Jl. Meranti, Kampus IPB Darmaga, Bogor 16680, Indonesia \\ ${ }^{3}$ Balai Besar Penelitian dan Pengembangan Bioteknologi dan Sumberdaya Genetik Pertanian \\ J1. Tentara Pelajar 3A, Bogor 16111 \\ ${ }^{4}$ Balai Besar Penelitian Tanaman Padi, Sukamandi, Jl. Raya IX, Sukamandi Subang, Indonesia
}

Diterima 10 Januari 2018/Disetujui 28 Juni 2018

\begin{abstract}
Doubled haploid rice formation through anther culture becomes one of the alternatives in the plant breeding. The lines need to be characterized, clustered, and selected. This study aimed at determining heritability, characters, and cluster of doubled haploid lines obtained from anther culture. This experiment was conducted at IPB Rice Field Experiment Station, Darmaga, Bogor from October 2016 until January 2017. The experiment was managed according to randomized complete block design (RCBD) with 3 replications and genotype as the single factor treatment. Genotypes used were 60 genotypes consisting of 56 doubled haploid lines and 4 control varieties. The controls were Ciherang, Inpara 5, Inpari 29, and Inpari 34 Salin Agritan. The results showed that all characters have significant effect and high heritability (above 60\%), so they could be used as a selection character. The tested genotypes could be grouped into three main groups. The first group consisted of 11 genotypes, the second group consisted of 44 genotypes, and the third group consisted of 5 genotypes. The main group determinant characters were productive tillers, percentage of filled grain number, plant height, panicle length, and weight of 1,000 grains. The number of filled grain and productive tillers can be used as selection characters together with yield potential.
\end{abstract}

Keywords: filled grain, heatmap, panicle length, productive tillers, yield potential

\section{ABSTRAK}

Pembentukan padi dihaploid melalui kultur antera menjadi salah satu alternatif dalam perakitan varietas, sehingga perlu untuk dikarakterisasi, dikelompokkan dan diseleksi. Penelitian ini bertujuan untuk mengetahui karakterisasi, heritabilitas dan pengelompokan terhadap galur-galur dihaploid hasil kultur antera. Percobaan dilakukan di Kebun Percobaan Sawah Baru IPB, Dramaga, Kabupaten Bogor pada bulan Oktober 2016 sampai Januari 2017. Rancangan percobaan yang digunakan ialah rancangan kelompok lengkap teracak (RKLT) dengan 3 ulangan dan satu faktor yaitu genotipe. Genotipe yang digunakan berjumlah 60 genotipe yang terdiri atas 56 galur $\mathrm{DH}_{2}$ dan 4 varietas pembanding yaitu Ciherang, Inpara 5, Inpari 29, dan Inpari 34 Salin Agritan. Hasil percobaan menunjukkan bahwa genotipe yang dikarakterisasi memiliki keragaman yang nyata pada semua karakter. Hal ini juga didukung dari nilai heritabilitas yang tinggi di atas $60 \%$, sehingga semua karakter berpotensi dijadikan sebagai karakter seleksi. Genotipe padi yang diuji dapat dikelompokkan menjadi tiga kelompok utama. Kelompok pertama terdiri atas 11 genotipe, kelompok kedua terdiri atas 44 genotipe, dan kelompok ketiga terdiri atas 5 genotipe. Pengelompokan tersebut ditentukan oleh anakan produktif, persentase jumlah gabah isi, tinggi tanaman, panjang malai, dan bobot 1,000 butir. Karakter anakan produktif dan jumlah gabah isi dapat dijadikan sebagai karakter seleksi bersama dengan karakter potensi hasil.

Kata kunci: anakan produktif, gabah isi, heatmap, panjang malai, potensial hasil

\footnotetext{
* Penulis untuk korespondensi. e-mail: bspurwoko@apps.ipb.ac.id
} 


\section{PENDAHULUAN}

Padi merupakan tanaman penting bagi masyarakat Indonesia. Hal ini dapat dilihat dari produksi padi Indonesia mencapai 72.7 juta ton GKG pada tahun 2016 yang mengalami peningkatan sebanyak 800 ribu ton dibandingkan tahun 2015 (FAO, 2016). Permintaan beras akan terus meningkat seiring dengan meningkatnya penduduk, sehingga diperlukan peningkatan produksi padi untuk memenuhi permintaan tersebut. Salah satu cara yang dapat dilakukan ialah merakit varietas padi unggul melalui konsep galur dihaploid.

Tanaman dihaploid (DH) memiliki konstitusi genetik yang homozigos, sehingga dapat memberikan keuntungan dalam meningkatkan keragaman, terutama karakter yang bersifat resesif, dan mempercepat perakitan varietas unggul (Dewi dan Purwoko, 2012). Perakitan varietas unggul secara konvensional memerlukan 8-10 generasi untuk membentuk galur dengan homozigositas yang tinggi. Akan tetapi, konsep pembentukan galur dihaploid hanya memerlukan satu generasi untuk membentuk populasi yang homozigos (Purwoko et al., 2010). Hal ini dapat mempersingkat waktu untuk memurnikan galur, dan seleksi dapat segera dilakukan. Safitri (2016) telah melakukan perakitan galur padi dihaploid melalui kultur antera dan mendapatkan 56 galur $\mathrm{DH}_{2}$ yang perlu diketahui heritabilitas dan karakter agronominya untuk memudahkan proses seleksi.

Heritabilitas merupakan rasio keragaman genetik terhadap keragaman fenotipe pada suatu karakter (Baloch et al., 2016). Parameter ini sangat penting dalam seleksi (Islam et al., 2015). Terdapat dua jenis nilai heritabilitas yaitu heritabilitas arti luas dan sempit. Heritabilitas arti sempit merepresentasikan pengaruh gen aditif terhadap fenotipenya, sehingga lebih sering digunakan untuk menentukan metode, tahapan dan karakter seleksi (Visscher et al., 2008). Heritabilitas arti sempit pada tanaman dihaploid memiliki nilai yang sama dengan arti luasnya (Dwivedi et al., 2015), sehingga heritabilitas arti luas dapat dijadikan dasar pertimbangan untuk memilih karakter seleksi.

Karakterisasi merupakan salah satu tahapan penting dalam program pemuliaan tanaman (Surahman et al., 2009). Karakterisasi dapat digunakan sebagai dasar dalam pengelompokan tanaman. Pengelompokan ini bertujuan untuk mengetahui hubungan kekerabatan antar genotipe tanaman dan dapat menjadi suatu bahan pertimbangan dalam proses seleksi. Seleksi melalui pengelompokan akan efektif apabila sifat-sifat dari kelompok tersebut dapat diketahui. Salah satu metode yang dapat digunakan adalah analisis clustergram.

Analisis clustergram merupakan analisis multivariat yang mengkombinasikan beberapa analisis kluster dalam suatu dimensi datar (Schonlau, 2002). Menurut Bowers (2010) analisis clustergram dengan kombinasi heatmap dan dendrogram hirarki akan menyederhanakan visualisasi dari analisis tersebut, sehingga lebih mudah dimengerti. Penggunaan analisis ini telah dilakukan oleh Zimisuhara et al. (2015) pada Ficus deltoidea, dan Yuan et al. (2016) pada kentang terhadap karakter-karakter morfologi. Selain itu, analisis ini juga sering digunakan untuk penelitian genomik (Wilkinson dan Friendly, 2009) dan metabolomik (Benton et al., 2015) untuk memudahkan visualisasi dari data set yang besar. Penggunaan analisis ini dapat memberikan pemahaman sederhana terkait dengan pengelompokan dan karakter penentu dari kelompok tersebut, sehingga dapat meningkatkan efektivitas seleksi (Yuan et al., 2016). Tujuan penelitian ini ialah untuk mengetahui heritabilitas, respon genotipe terhadap karakterisasi, dan pengelompokan genotipe beserta penentu kelompoknya berdasarkan karakter fenotipik tanaman sebagai dasar seleksi pada 56 galur padi dihaploid hasil kultur antera.

\section{BAHAN DAN METODE}

Percobaan dilakukan di Kebun Percobaan Sawah Baru IPB, Dramaga, Kabupaten Bogor pada bulan Oktober 2016 sampai Januari 2017. Rancangan percobaan yang digunakan ialah rancangan kelompok lengkap teracak (RKLT) dengan satu faktor yaitu genotipe. Genotipe yang digunakan berjumlah 60 genotipe yang terdiri atas 56 galur dihaploid dan 4 varietas pembanding yaitu Ciherang, Inpara 5, Inpari 29, dan Inpari 34 salin Agritan. Galur dihaploid yang diujikan merupakan galur $\mathrm{DH}_{2}$ dari hasil 4 persilangan yaitu Inpara 5/IR77674 (HS1), IR77674/Inpari 29 (HS4), IR78788/Inpari 29 (HS14), dan Dendang/Inpari 30. Setiap genotipe diulang tiga kali, sehingga jumlah satuan percobaan sebanyak 180 satuan percobaan. Setiap satuan percobaan terdiri atas 24 tanaman yang ditanam dalam dua baris.

Benih disemai pada bak yang ditempatkan di rumah kaca. Setiap genotipe disemai sebanyak $10 \mathrm{~g}$. Bibit hasil persemaian dipindah tanam (transplanting) setelah berumur 18 hari ke sawah yang telah diolah sebelumnya. Jarak tanam yang digunakan adalah $25 \mathrm{~cm}$ x $25 \mathrm{~cm}$ dengan tiga bibit per lubang tanam dan dilakukan penyulaman pada 1 MST. Pemeliharaan meliputi pemupukan dengan dosis 200 $\mathrm{kg}$ urea, $100 \mathrm{~kg}$ SP-36, dan $100 \mathrm{~kg} \mathrm{KCl} \mathrm{ha-1}$. Pupuk urea diberikan secara bertahap dengan proporsi $1 / 3$ dosis pada awal tanam, 28 hari setelah tanam (HST) dan pada umur 49 HST. Padi yang siap untuk dipanen ditandai dengan $80 \%$ bulir padi telah menguning.

Pengamatan karakter kuantitatif dilakukan terhadap tinggi tanaman, jumlah anakan produktif, umur berbunga, panjang malai, bobot 1,000 butir, jumlah gabah isi per malai, jumlah gabah total, persentase jumlah gabah isi, dan potensi hasil. Data dianalisis berdasarkan komponen ragam, heritabilitas arti luas, rata-rata dan rentang nilainya (Safitri, 2016). Selain itu analisis pengelompokan genotipe dilakukan menggunakan software R-package d3heatmap (Cheng et al., 2016).

\section{HASIL DAN PEMBAHASAN}

\section{Parameter Genetik Populasi Padi Dihaploid}

Nilai heritabilitas diperoleh melalui kuadrat tengah pada rancangan percobaan (Ogunbayo et al., 2014; Nirmaladevi et al., 2015; Baloch et al., 2016). Semua 
Tabel 1. Hasil sidik ragam (ANOVA) dan parameter genetik populasi padi dihaploid

\begin{tabular}{lccccccccc}
\hline SK & TT & AP & UB & PM & PH & B1000 & JGI & JGT & PJGI \\
\hline Ul & 8.10 & $18.53^{* *}$ & 3.94 & $34.81^{* *}$ & $12.29^{* *}$ & 0.74 & $8,208.90^{* *}$ & $2,812.20^{* *}$ & $1,664.50^{* *}$ \\
G & $100.16^{* *}$ & $13.36^{* *}$ & $66.73^{* *}$ & $9.67^{* *}$ & $1.76^{* *}$ & $12.21^{* *}$ & $691.80^{* *}$ & $2,702.70^{* *}$ & $159.30^{* *}$ \\
Galat & 13.73 & 3.71 & 1.47 & 1.32 & 0.53 & 2.19 & 255.10 & 222.00 & 56.71 \\
KK & 3.67 & 10.88 & 1.51 & 4.05 & 15.96 & 5.12 & 14.35 & 9.34 & 10.66 \\
VG & 28.81 & 3.22 & 21.75 & 2.79 & 0.41 & 3.34 & 145.56 & 826.90 & 34.21 \\
VP & 33.39 & 4.45 & 22.24 & 3.22 & 0.59 & 4.07 & 230.61 & 900.91 & 53.11 \\
$\mathrm{~h}^{2}$ & 86.29 & 72.26 & 97.80 & 86.40 & 69.83 & 82.00 & 63.12 & 91.79 & 64.41 \\
\hline Ks & & & & & & & & &
\end{tabular}

Keterangan: * signifikan pada taraf 5\%,** signifikan pada taraf $1 \%, \mathrm{SK}=$ sumber keragaman, $\mathrm{Ul}=$ ulangan, $\mathrm{G}=$ genotipe, $\mathrm{KK}=$ koefisien keragaman, $\mathrm{TT}=$ tinggi tanaman, $\mathrm{AP}=$ anakan produktif, $\mathrm{UB}=$ umur berbunga, $\mathrm{PM}=$ panjang malai, $\mathrm{PH}=$ potensi hasil, $\mathrm{B} 1000=$ bobot 1,000 butir, JGI $=$ jumlah gabah isi, $\mathrm{JGT}=$ jumlah gabah total, $\mathrm{PJGI}=$ persentase jumlah gabah isi, $\mathrm{VG}=\mathrm{ragam}$ genetik, $\mathrm{VP}=$ ragam fenotipe, $\mathrm{h}_{\mathrm{bs}}{ }_{\mathrm{bs}}=$ heritabilitas arti luas

karakter yang diamati menunjukkan keragaman yang sangat nyata (Tabel 1). Hal ini menjelaskan adanya perbedaan fenotipe yang besar diantara galur-galur dihaploid yang diuji. Selain itu, nilai heritabilitas semua karakter berada di atas $60 \%$, diklasifikasikan sebagai heritabilitas yang tinggi (Johnson et al., 1955). Heritabilitas yang tinggi mencerminkan pengaruh genetik lebih besar dibandingkan pengaruh lingkungannya. Karakter yang memiliki nilai heritabilitas tertinggi ialah umur berbunga sebesar $97.80 \%$, diikuti oleh jumlah gabah total (JGT) dan panjang malai (PM). Sebaliknya nilai heritabilitas terendah dimiliki oleh jumlah gabah isi sebesar 63.12\%. Ogunbayo et al. (2014) dan Fathelrahman et al. (2015) juga melaporkan bahwa umur berbunga merupakan karakter yang memiliki nilai heritabilitas yang tinggi.

Tanaman dihaploid tidak memiliki lokus yang bersifat heterozigos atau 100\% lokusnya bersifat homozigos (Dewi dan Purwoko, 2012; Dwivedi et al., 2015). Hal ini menjadikan tanaman dihaploid tidak memiliki aksi gen dominan yang mempengaruhi karakter-karakternya (Seymour et al., 2011), sehingga karakternya dapat diwariskan secara menyeluruh. Oleh sebab itu, karakter dengan nilai heritabilitas yang tinggi dapat digunakan sebagai karakter seleksi yang dapat meningkatkan efektifitas seleksi (Cegielska-Taras et al., 2015). Berdasarkan analisis diatas seluruh karakter pengamatan dapat dijadikan sebagai karakter seleksi.

\section{Karakterisasi Galur-galur Padi Dihaploid}

Rata-rata tinggi tanaman dari 60 genotipe sebesar $100.87 \mathrm{~cm}$ dengan rentang antara 76.10-107.95 cm (Tabel 2). Menurut Yoshida (1981) tinggi tanaman sangat terkait dengan partisi biomassa dan umur suatu tanaman. Semakin tinggi tanaman padi akan berdampak pada umur tanaman yang lebih lama. Menurut Safitri (2016) berdasarkan tinggi tanaman, padi sawah dapat dikelompokkan menjadi tiga kelompok, yaitu pendek $(<110 \mathrm{~cm})$, sedang $(110-130 \mathrm{~cm})$ dan tinggi $(>130 \mathrm{~cm})$. Berdasarkan pengelompokan di atas, semua genotipe tergolong pendek, yang menggambarkan rata-rata genotipe berumur cukup genjah.
Rata-rata umur berbunga sebesar 80.5 hari dengan kisaran 75-90 hari (Tabel 2). Menurut Yoshida (1981) umur berbunga berkaitan dengan umur tanaman karena fase generatif dan ripening pada padi relatif sama, sehingga yang membedakan umur tanaman ialah fase vegetatifnya. Selain itu, rata rata petani menyukai padi yang lebih genjah, sehingga umur berbunga yang genjah merupakan indikator yang penting. Pada penelitian ini, terdapat 46 galur dihaploid yang memiliki umur lebih genjah dibandingkan varietas Ciherang (83.8 hari) yang merupakan varietas populer.

Rata-rata anakan produktif yang dihasilkan sebesar 17.70 dengan kisaran 13-21 anakan (Tabel 2). Anakan produktif merupakan anakan yang menghasilkan malai, sehingga sangat terkait dengan produksi tanaman. Menurut Safitri (2016) berdasarkan jumlah anakan produktif tanaman padi terbagi menjadi lima golongan, yaitu sangat banyak ( $>$ 25 anakan), banyak (20-25 anakan), sedang (10-19 anakan), sedikit (5-9 anakan) dan sangat sedikit $(<5$ anakan). Pada penelitian ini terdapat 14 genotipe yang tergolong memiliki anakan produktif banyak dan 46 lainnya tergolong sedang.

Panjang malai populasi ini rata-rata sebesar $28.31 \mathrm{~cm}$ dengan rentang 22.64-31.29 cm (Tabel 2). Menurut Yoshida (1981) panjang malai merupakan karakter yang menentukan kapasitas jumlah gabah per malai. Pada penelitian ini, terdapat 54 galur dihaploid yang memiliki malai lebih panjang dibandingkan Ciherang $(24.23 \mathrm{~cm})$.

Bobot 1,000 butir rata-rata sebesar $28.91 \mathrm{~g}$ dengan rentang 24.30-32.65 g yang diukur pada kadar air 14\%. Menurut Abdullah et al. (2008) rata-rata bobot 1,000 butir secara umum berkisar 25-27 g. Pada penelitian ini terdapat satu genotipe yang memiliki bobot 1,000 butir dibawah 25 g, 5 genotipe tergolong dalam rentang 25-27 g, dan genotipe lainnya memiliki nilai $>27$ g. Menurut Yoshida (1981) bobot 1,000 butir merupakan salah satu penentu produksi padi beserta jumlah anakan produktif, dan jumlah gabah isi per malai, sehingga pengamatan terhadap karakter ini penting untuk dilakukan.

Rata rata jumlah gabah total, dan gabah isi secara berturut-turut sebesar 159.4 dan 111.1 dengan rentang antara 117.1-235.6, dan 77.1-153.1 (Tabel 2). Karakter-karakter 
tersebut sangat terkait dengan potensi produksi suatu tanaman. Hal tersebut juga disampaikan oleh Safitri (2016) yang menyatakan bahwa salah satu karakter yang dimiliki oleh varietas unggul ( $>9$ ton $\left.\mathrm{ha}^{-1}\right)$ adalah jumlah gabah per malai yang berkisar 150-250 butir dengan persentase pengisian sebesar $85-95 \%$. Pada penelitian ini tidak terdapat galur yang memenuhi syarat varietas unggul sesuai Safitri (2016). Akan tetapi, terdapat 32 galur dihaploid yang memiliki jumlah butir lebih dari 150, walaupun persentase jumlah gabah isinya tidak melebih $85 \%$.

Karakter terakhir yang diamati ialah produktivitas atau potensi hasil. Produktivitas merupakan karakter utama yang digunakan sebagai kriteria seleksi dalam seleksi langsung. Galur dengan produktivitas yang tinggi dan melebihi varietas pembanding dapat dijadikan sebagai kandidat varietas unggul baru. Rata rata produktivitas populasi ini

Tabel 2. Karakterisasi galur-galur terbaik padi dihaploid di Dramaga, Bogor pada bulan Oktober 2016 hingga Januari 2017

\begin{tabular}{|c|c|c|c|c|c|c|c|c|c|c|}
\hline Label & Genotipe & $\mathrm{TT}(\mathrm{cm})$ & $\mathrm{AP}$ & $\begin{array}{c}\text { UB } \\
\text { (hari) }\end{array}$ & $\begin{array}{l}\mathrm{PM} \\
(\mathrm{cm})\end{array}$ & $\begin{array}{c}\text { B1000 } \\
(\mathrm{g})\end{array}$ & JGI & JGT & $\begin{array}{c}\text { PJGI } \\
(\%) \\
\end{array}$ & $\begin{array}{c}\mathrm{PH} \\
\text { (ton ha-1) }^{-1}\end{array}$ \\
\hline F15 & HS4-11-1-36 & 106.29 & 13.7 & 88.7 & 31.14 & 31.80 & 133.9 & 235.6 & 57.16 & 4.94 \\
\hline F16 & HS4-11-1-70 & 107.56 & 13.9 & 88.1 & 30.71 & 31.55 & 153.1 & 230.6 & 67.38 & 5.17 \\
\hline F19 & HS4-11-1-73 & 106.65 & 15.1 & 88.3 & 29.56 & 32.65 & 124.0 & 212.3 & 58.01 & 5.26 \\
\hline F20 & HS4-11-1-74 & 99.33 & 15.3 & 90.1 & 30.28 & 30.75 & 113.0 & 199.2 & 56.92 & 5.07 \\
\hline F21 & HS4-11-1-75 & 102.00 & 13.1 & 87.6 & 29.07 & 31.60 & 134.4 & 216.7 & 61.47 & 5.05 \\
\hline F22 & HS4-15-1-6 & 99.79 & 19.7 & 81.0 & 28.33 & 27.55 & 123.3 & 162.7 & 75.81 & 5.49 \\
\hline F32 & HS4-15-1-28 & 106.01 & 20.1 & 81.3 & 29.15 & 28.80 & 125.2 & 165.3 & 75.52 & 5.25 \\
\hline F34 & HS4-15-1-43 & 101.77 & 18.3 & 82.0 & 28.83 & 28.30 & 123.6 & 168.4 & 73.43 & 4.92 \\
\hline F36 & HS4-15-1-62 & 102.99 & 18.4 & 81.0 & 30.43 & 26.65 & 133.4 & 180.3 & 74.68 & 5.31 \\
\hline F37 & HS4-15-1-63 & 96.93 & 20.9 & 80.2 & 29.46 & 27.50 & 108.5 & 157.6 & 68.76 & 5.29 \\
\hline F38 & HS4-15-1-64 & 101.32 & 20.0 & 81.0 & 29.71 & 27.25 & 126.0 & 174.2 & 71.77 & 5.38 \\
\hline F39 & HS4-15-1-70 & 102.01 & 19.7 & 81.7 & 28.99 & 27.95 & 129.6 & 171.5 & 75.07 & 5.22 \\
\hline F40 & HS4-15-2-4 & 100.65 & 21.3 & 76.8 & 29.63 & 28.60 & 123.7 & 155.5 & 79.03 & 5.52 \\
\hline F41 & HS4-15-2-6 & 103.34 & 20.9 & 81.3 & 28.69 & 28.75 & 121.2 & 163.1 & 74.00 & 5.97 \\
\hline F42 & HS4-15-2-9 & 102.26 & 20.3 & 81.4 & 28.53 & 27.35 & 115.6 & 161.7 & 70.86 & 5.29 \\
\hline F43 & HS4-15-3-4 & 98.93 & 19.3 & 81.8 & 28.61 & 28.40 & 122.1 & 169.4 & 72.61 & 5.96 \\
\hline F44 & HS4-15-3-5 & 102.28 & 19.2 & 81.2 & 28.73 & 27.10 & 130.2 & 169.2 & 76.51 & 5.66 \\
\hline F45 & HS4-15-3-6 & 100.26 & 19.2 & 81.0 & 28.57 & 27.85 & 115.3 & 156.8 & 73.37 & 4.88 \\
\hline F46 & HS4-15-3-8 & 101.66 & 20.5 & 82.1 & 27.71 & 26.85 & 118.2 & 161.0 & 72.94 & 5.60 \\
\hline F47 & HS4-15-3-17 & 102.35 & 20.1 & 81.1 & 30.73 & 29.90 & 116.3 & 158.1 & 73.18 & 6.00 \\
\hline F48 & HS4-15-3-26 & 96.46 & 18.6 & 80.9 & 28.11 & 26.40 & 106.5 & 148.5 & 72.14 & 4.61 \\
\hline F49 & HS4-15-3-29 & 101.43 & 20.4 & 81.3 & 28.43 & 28.20 & 110.4 & 155.9 & 70.93 & 5.65 \\
\hline F50 & HS4-15-3-30 & 101.83 & 19.1 & 82.1 & 28.25 & 27.70 & 106.8 & 151.0 & 70.26 & 5.03 \\
\hline F51 & HS4-15-3-32 & 104.31 & 19.9 & 81.4 & 29.51 & 27.70 & 130.6 & 171.7 & 75.94 & 6.03 \\
\hline F52 & HS4-45-1-66 & 98.77 & 18.1 & 79.6 & 28.46 & 28.30 & 111.9 & 158.8 & 70.45 & 4.71 \\
\hline F57 & Ciherang & 86.31 & 17.8 & 83.8 & 24.23 & 26.20 & 102.0 & 136.4 & 73.99 & 4.26 \\
\hline F58 & Inpara 5 & 76.10 & 21.0 & 79.3 & 24.75 & 26.35 & 88.7 & 119.3 & 74.29 & 3.74 \\
\hline F59 & Inpari 29 & 97.64 & 15.3 & 86.0 & 30.17 & 28.35 & 128.8 & 210.8 & 61.66 & 4.45 \\
\hline F60 & $\begin{array}{l}\text { Inpari } 34 \\
\text { Salin Agritan }\end{array}$ & 103.82 & 17.0 & 81.9 & 25.27 & 26.55 & 126.4 & 149.4 & 85.04 & 4.47 \\
\hline Rata-rata & & 100.87 & 17.7 & 80.5 & 28.31 & 28.91 & 111.1 & 159.4 & 70.53 & 4.56 \\
\hline Maksimum & & 107.95 & 21.2 & 90.1 & 31.29 & 32.65 & 153.1 & 235.6 & 85.04 & 6.03 \\
\hline Minimum & & 76.10 & 13.1 & 74.6 & 22.64 & 24.30 & 77.1 & 117.1 & 48.16 & 2.99 \\
\hline
\end{tabular}

Keterangan: $\mathrm{TT}=$ tinggi tanaman, $\mathrm{AP}=$ anakan produktif, $\mathrm{UB}=$ umur berbunga, $\mathrm{PM}=$ panjang malai, $\mathrm{B} 1000=$ bobot 1,000 butir, JGI $=$ jumlah gabah isi, $\mathrm{JGT}=$ jumlah gabah total, $\mathrm{PJGI}=$ persentase jumlah gabah isi, $\mathrm{PH}=$ potensi hasil, $\mathrm{HS} 4=$ galur hasil persilangan IR77674/Inpari 29 
sebesar 4.56 ton $\mathrm{ha}^{-1}$ dengan rentang 2.99-6.03 ton $\mathrm{ha}^{-1}$, sementara empat varietas pembanding yang digunakan yaitu Ciherang (4.26 ton ha ${ }^{-1}$ ), Inpara 5 ( 3.74 ton ha ${ }^{-1}$ ), Inpari 29 (4.45 ton $\mathrm{ha}^{-1}$ ), dan Inpari 34 Agritan (4.47 ton $\mathrm{ha}^{-1}$ ). Berdasarkan hasil penelitian ini, terdapat 29 galur yang memiliki produktivitas lebih tinggi dibandingkan varietas unggul terbaik (Inpari 34 Salin Agritan), walaupun nilai potensi hasil galur-galur tersebut tidak mencapai 9 ton ha- ${ }^{-1}$. Produktivitas yang tidak maksimum ini diduga disebabkan oleh salinitas tanah yang moderat $(3.9 \mathrm{dS} / \mathrm{m})$ dan penerapan sistem irigasi intermitten, sehingga lahan pada kondisi tidak optimal. Menurut Ghosh et al. (2016) salinitas pada lahan berdampak pada penurunan produksi tanaman. Dampak tersebut terlihat dari produksi varietas pembanding yang tidak mencapai potensi hasilnya.

\section{Pengelompokan Padi Dihaploid Berdasarkan Analisis Clustergram}

Analisis ini menggunakan warna merah sebagai kekuatan keeratannya. Pada gambar tersebut, terdapat dua jenis dendrogram yaitu dendrogram genotipe yang bertindak sebagai baris dan dendrogram karakter morfologi yang bertindak sebagai kolom. Dendrogram karakter morfologi menunjukkan terdapat 3 kelompok yaitu potensi hasil (PH), jumlah gabah isi (JGI), jumlah gabah total (JGT), dan umur berbunga (UB) sebagai kelompok pertama; bobot 1,000 butir (B1000), tinggi tanaman (TT), dan panjang malai (PM) sebagai kelompok 2; anakan produktif (AP) dan persentase jumlah gabah isi (PJGI) sebagai kelompok 3 (Gambar 1). Pengelompokan karakter ini didasarkan pada kemiripan pola timbal balik antara karakter tersebut dengan genotipe, sehingga pola tersebut dapat dijadikan pertimbangan dalam meningkatkan efesiensi seleksi (Yuan et al., 2016).

Dendrogram genotipe juga terdiri atas 3 kelompok besar (Gambar 1). Kelompok genotipe pertama terdiri atas 11 genotipe yang terbagi menjadi dua subkelompok. Pengelompokan ini didasarkan pada bobot 1,000 butir, jumlah gabah total, dan umur berbunga yang tinggi serta anakan produktif dan persentase jumlah gabah isi yang sangat rendah. Pengelompokan untuk subkelompok didasarkan pada jumlah gabah isi. Subkelompok yang terdiri

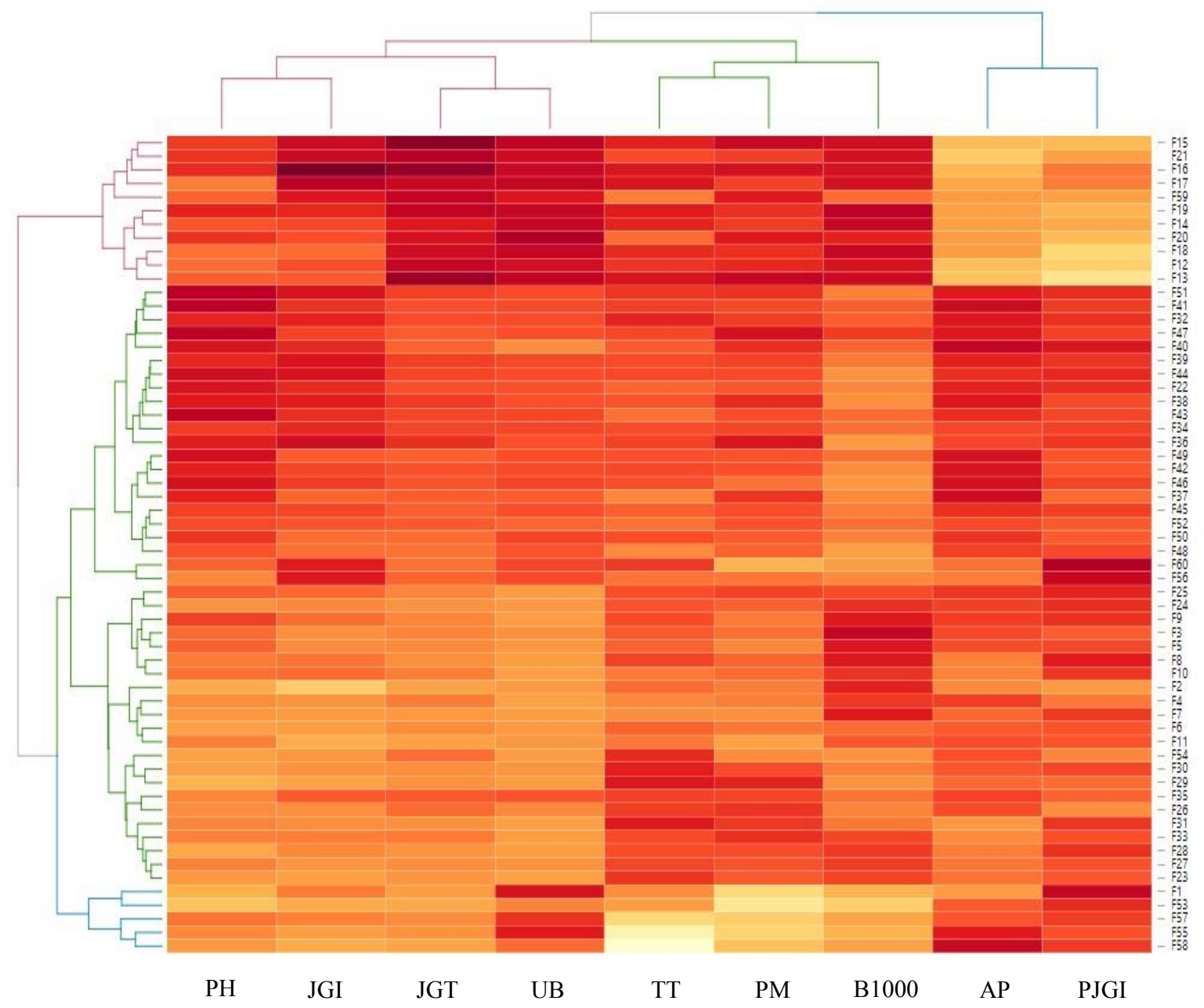

Gambar 1. Analisis clustergram dengan konsep heatmap terhadap 60 genotipe dan 9 karakter pada percobaan karakterisasi di kebun percobaan Sawah Baru IPB bulan Oktober 2016 hingga Januari 2017. TT $=$ tinggi tanaman, AP $=$ anakan produktif, UB $=$ umur berbunga, $\mathrm{PM}=$ panjang malai, $\mathrm{B} 1000=$ bobot 1,000 butir, $\mathrm{JGI}=$ jumlah gabah isi, $\mathrm{JGT}=$ jumlah gabah total, $\mathrm{PJGI}=$ persentase jumlah gabah isi, $\mathrm{PH}=$ potensi hasil 
atas F15, F16, F17, F21, dan F59 memiliki jumlah gabah isi yang lebih tinggi dibandingkan subkelompok lainnya (F19, F14,F12, F18, F20, dan F13). Galur F15, F16, F19, F20 dan F21 merupakan galur dengan potensi hasil tertinggi pada kelompok tersebut. Galur-galur tersebut juga memiliki jumlah gabah isi dan bobot 1,000 butir yang lebih tinggi dibandingkan anggota lainnya dalam kelompok ini.

Kelompok kedua merupakan kelompok terbesar diantara tiga kelompok yang ada. Kelompok ini terdiri atas 44 anggota yang terbagi dalam dua subkelompok yang setiap subkelompoknya memiliki 3-4 subsubkelompok. Kelompok ini didasarkan pada nilai genotipe yang berada di sekitar rata-rata pada setiap karakter. Hal ini dapat dilihat dari warna yang hampir merata pada setiap karakter dan tidak adanya warna ekstrim terang pada karakter-karakter tersebut. Adapun karakter pembeda dari kedua subkelompok ini ialah potensi hasil, jumlah gabah isi, umur berbunga, bobot 1,000 butir, dan anakan produktif. Subkelompok pertama terdiri atas 20 anggota yang memiliki potensi hasil, umur berbunga, jumlah gabah isi, dan anakan produktif relatif lebih besar, tetapi memiliki bobot 1,000 butir yang relatif lebih rendah dibandingkan subkelompok kedua.

Kelompok ketiga merupakan kelompok pencilan yang terdiri atas 5 genotipe (F1, F53, F57, F55, dan F58). Kelompok ini ditentukan oleh tinggi tanaman, panjang malai, dan bobot 1,000 butir yang sangat rendah serta anakan produktif dan persentase jumlah gabah isi yang cukup tinggi. Namun potensi hasil kelompok ini tergolong relatif rendah, sehingga tidak ada galur yang dapat diseleksi pada kelompok ini.

Perbedaan antar kelompok genotipe sangat jelas oleh adanya warna ekstrim terang pada karakter TT, PM, B1000, AP, dan PJGI, dan ekstrim gelap pada karakter JGT (Gambar 1). Menurut Lee et al. (2016) intensitas warna pada analisis clustergram menunjukkan tingkat kekuatan atau derajat genotipe pada setiap karakter. Semakin gelap warna suatu genotipe terhadap suatu karakter maka semakin tinggi nilai genotipe terhadap karakter tersebut. Hal ini dapat memberikan pemahaman yang mudah dalam menentukan sifat-sifat kelompok genotipe dengan melihat kontras warna antar kelompok.

Subkelompok pertama pada kelompok genotipe ke dua merupakan subkelompok terbaik yang dapat diseleksi dan diteruskan pada generasi selanjutnya. Hal ini dapat dilihat dari pola intensitas warna yang kuat pada karakter potensi hasil, jumlah gabah isi, dan anakan produktif. Pola warna ini menjelaskan bahwa potensi hasil memiliki korelasi yang tinggi dengan karakter-karakter tersebut, sehingga dapat dipertimbangkan sebagai karakter seleksi. Berdasarkan hasil tersebut, pengelompokan dengan clustergram dapat memberikan gambaran dalam melakukan seleksi secara sederhana. Hal ini berbeda dengan dendrogram pada umumnya yang hanya memberikan informasi pengelompokan dan derajat kekerabatan genotipenya (Indhirawati et al., 2015), sehingga informasi yang diberikan tidak terlalu luas.

\section{KESIMPULAN}

Genotipe menunjukkan respon yang sangat beragam pada seluruh karakter. Semua karakter pengamatan memiliki heritabilitas yang tinggi dan berpotensi sebagai karakter seleksi. Genotipe padi yang diujikan dapat dikelompokkan menjadi tiga kelompok utama. Anakan produktif, persentase jumlah gabah isi, tinggi tanaman, panjang malai, dan bobot 1,000 butir merupakan karakter penentu kelompok. Karakter jumlah gabah isi dan anakan produktif dapat dijadikan sebagai karakter seleksi bersama dengan karakter potensi hasil.

\section{UCAPAN TERIMAKASIH}

Terima kasih disampaikan kepada Kementerian Riset, Teknologi, dan Pendidikan Tinggi yang telah memberikan dana untuk melaksanakan penelitian ini melalui Program Penelitian Pendidikan Magister Menuju Doktor untuk Sarjana Unggul (PMDSU).

\section{DAFTAR PUSTAKA}

Abdullah, B., S. Tjokrowidjojo, Sularjo. 2008.Perkembangan dan prospek perakitan padi tipe baru di Indonesia. J Litbang Pert. 27:1-9.

Baloch, A.W., S.M. Bhatti, M. Baloch, Q.D. Jogi, M.N. Kandhro. 2016. Correlation analysis of various metric traits with grain yield and heritability estimation in rice genotypes. Pak. J. Agric, Agric. Eng. Vet. Sci. 32:136-142.

Benton, H.P., J. Ivanisevic, D. Rinehart, A. Epstein, M.E. Kurczy, M.D.Boska, H.E. Gendelman, G. Siuzdak. 2015. An interactive cluster heatmap to visualize and explore multidimensional metabolomic data. Metabolomics 11:1029-1034.

Bowers, A.J. 2010. Analyzing the longitudinal K-12 grading histories of entire cohorts of students: grades, data driven decision making, dropping out and hierarchical cluster analysis. Practical Assessment. Res. Eval. 15:1-18.

Cegielska-Taras, T., L. Szala, M. Matuszczak, BabulaSkowrońska, K. Mikolajczyk, W. Poplawska, K. Sosnowska, B. Hernacki, A. Olejnik, I. BartkowiakBroda. 2015. Double haploids as a material for biotechnological manipulation and as a modern tool for breeding oilseed rape (Brassica napus L.). BioTecnologia 96:7-18.

Cheng, J., T. Galili, Rstudio, M. Bostock, J. Palmer. 2016. Package 'd3heatmap'. http:/git.hub.com/rstudio/ d3heatmap [10 September 2017]. 
Dewi, I.S., B.S. Purwoko. 2012. Kultur antera untuk percepatan perakitan varietas padi di Indonesia. J. AgroBiogen 8:78-88.

Dwivedi, S.L., A.B. Britt, L. Tripathi, S. Sharma, H.D. Upadhyaya, R. Ortiz. 2015. Haploids: constraints and opportunities in plant breeding. Biotechnol. Adv. 2015:1-18.

[FAO] Food and Agriculture Organization. 2016. Rice market monitor. Volume XIX no 4. http://www.fao. org/economic/RMM [19 Juni 2017].

Fathelrahman, S.A., A.I. Alsadig, Y.I. Dagash. 2015. Genetic variability in rice genotypes (Oryza sativa L.) in yield and yield component under semi-arid zone (Sudan). J. Forest Products Industries 4:21-32.

Ghosh, B., Md.N. Ali, G. Saikat. 2016. Response of rice under salinity stress: a review update. J. Res. Rice 4:167. doi : 10.4172/2375-4338.1000167.

Indhirawati, R., A. Purwantoro, P. Basunanda. 2015. Karakterisasi morfologi dan molekuler jagung berondong stroberi dan kuning (Zea mays L. kelompok everta). Vegetalika 4:102-114.

Islam, M.A., S.A. Raffi, M.A. Hossain, A.K. Hasan. 2015. Analysis of genetic variability, heritability, and genetic advance for yield and yield associated traits in some promising advanced lines of rice. Progressive Agric. 26:26-31.

Johnson, H.W., H.F. Robinson, R.E. Comstock. 1955. Estimates of genetic and environmental variability in soybean. Agron. J. 47:314-318.

Lee, J.E., M. Recker, A.J. Bowers, M. Yuan. 2016. Hierarchical cluster analysis heatmaps and pattern analysis: an approach for visualizing learning management system intercation data. Proceeding of The 9th International Conference on Educational Data Mining. North Corolina. USA 29 June-2 July 2016.

Nirmaladevi, G., G. Padmavathi, S. Kota, V.R. Babu. 2015. Genetic variability, heritability, and correlation coefficients of grain quality characters in rice (Oryza sativa L.). Sabrao J. Breed. Genet. 47:424-433.

Ogunbayo, S.A., M. Sié, D.K. Ojo, K.A. Sanni, G. Akinwale, B. Toulou, A. Shittu, E.O. Idehen, A.R. Popoola, I.O.
Daniel, G.B. Gregorio. 2014. Genetic variation and heritability of yield and related traits in promising rice genotypes (Oryza sativa L.). J. Plant Breed. Crop Sci. 6:153-159.

Purwoko, B.S., I.S. Dewi, N. Khumaida. 2010. Rice anther culture to obtain doubled-haploids with multiple tolerances. Asia Pacific J. Mol. Biol. Biotechnol. 18:55-57.

Safitri, H. 2016. Pengembangan padi toleran salinitas melalui kultur antera. Disertasi. Sekolah Pascasarjana. Institut Pertanian Bogor. Bogor.

Schonlau, M. 2002. The clustergram : A graph for visualizing hierarchical and nonhierarchical cluster analyses. Stata J. 2:391-402.

Seymour, D.K., D.L. Filiault, I.M. Henry, J. Monson-Miller, M. Ravi, A. Pang, L. Comai, S.W.L. Chan, J.N. Maloof. 2011. Rapid creation of Arabidopsis double haploid lines for quantitative trait locus mapping. PNAS. 109:4227-4232.

Surahman, M., E. Santosa, F.N. Nisya. 2009. Karakterisasi dan analisis gerombol plasma nutfah jarak pagar Indonesia dan beberapa negara lain menggunakan marka morfologi dan molekuler. J. Agron. Indonesia 37:256-264.

Visscher, P.M., W. G. Hill, N.R. Wray. 2008. Heritability in genomics era-concepts and misconceptions. Nat. Rev. 9:255-266.

Wilkinson, L., M. Friendly. 2009. The history of the cluster heatmap. The American Statistician 63:179-184.

Yoshida, S. 1981. Fundamentals of Rice Crop Science. The Internastional Rice Research Institute. Los Banos, Philippines.

Yuan, J., A. Murphy, D.D. Koeyer, M. Lague, B. Bizimungu. 2016. Effectiveness of the field selection parameters on potato yield in Atlantic Canada. Can. J. Plant Sci. 96:701-710.

Zimisuhara, B., A. Valdiani, N.A. Shaharuddin, F. Qamaruzzaman, M. Maziah. 2015. Structure and principal component analyses reveal an intervarietal fusion in Malaysia mistleteo fig (Ficus deltoidea Jack) population. Int. J. Mol. Sci. 16:14369-14394. 